\title{
Fernando Pessoa lido na Romênia atual
}

Micaela Ghitescu

União dos Escritores Romenos

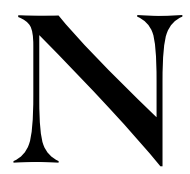

a Romênia de hoje, vários textos de Pessoa poderiam abalar inteligências sólidas e perturbar sensibilidades mais ou menos instáveis. A sua oportunidade para o nosso meio social, político e intelectual é indiscutível. Trechos como os seguintes são perfeitamente atuais: "Há muitas coisas que se executam por palpite, imensas que se fazem empiricamente, pelo hábito e a experiência. Mas a organização estável, ou seja a organização propriamente dita, é um trabalho de inteligência." " Ou então: "Todos os processos e os aparelhos resultarão elementos inúteis de organização se as cabeças dos indivíduos que os empregam não estiverem organizadas também."” E Pessoa afirma ainda: "Não digo [...] organização perfeita porque organizar quer dizer organizarperfeitamente; organização imperfeita não é organização."

Com essa ironia em epígrafe gostaríamos de realizar um "Manual dos homens políticos e de negócios" da autoria de Fernando Pessoa, válido não só para o Portugal do início do século XX, mas também para a Romênia do início do século XXI que conheceu a "desorganização" comunista!

Depois desse mergulho algo abrupto em textos pessoanos (datados de 1918, 1919 e 1926) que tomei particularmente a peito - como romena e cidadã desse país que atravessou uma transição "que nunca mais acabava" (como costumavamos dizer) -, vou sistematizar meu ensaio, detendo-me primeiro, sumariamente, no material usado por mim, como tradutora, isto é, na língua romena que - apesar de ser irmã, pela latinidade, do português - continua "terra incógnita" para a maioria dos

\footnotetext{
${ }^{1}$ PESSOA, 2000, p. 19.

${ }^{2}$ PESSOA, 2000, p. 23.

${ }^{3}$ PESSOA, 2000, p. 26.
} 
lusofalantes (a menos que sejam filólogos); depois, também muito brevemente, vou abordar a "história" das minhas traduções pessoanas; para deter-me, afinal, mais longamente, naqueles textos que possam constituir "a lição de Fernando Pessoa" para os meus compatriotas e coetâneos.

Antes de tudo vou indicar alguns - poucos - elementos que tornam singular o romeno entre as demais línguas novilatinas, ou que o aproximam do português.

O romeno (que se formou na antiga "Dacia Felix" - uma das últimas regiões conquistadas pelo Império Romano) é a única língua novilatina que sobreviveu na Europa Oriental. Apesar de seu isolamento e das invasões bárbaras, os romenos permaneceram fieis a suas origens latinas, fidelidade ajudada no Oriente pela existência do Império Bizantino, quer dizer gregolatino, e a propagação do Cristianismo. A mais importante das invasões foi dos eslavos, no século VI, que deixaram rastos no léxico e na fonética.

Outra invasão de monta foi a dos húngaros, no século XI, na Transilvânia, com uma influência menor, limitada a empréstimos lexicais.

No século XVIII, os Principados Romenos caíram sob o domínio dos turcos (até a Guerra de Independência de 1877). A sua influência, a que se acrescentou o grego, restringiu-se também ao vocabulário.

Mas a língua romena foi mais conservadora do que as demais línguas novilatinas, por existir numa área periférica. Um exemplo seria o fato de que é a única a manter as declinações latinas.

Outra singularidade, devida às influências mencionadas, é a extensa sinonimia de que beneficiamos (sobretudo nós, os tradutores literários). Temos a possibilidade de jogar com os sinónimos, o que dá mais flexibilidade ao estilo e, ao mesmo tempo, desempenha um importante papel eufónico. Darei só dois exemplos: "obter" pode dizerse a obpine (do latim) e a dobândi (do eslavo); "prometer" pode dizer-se a promite (do latim) e a făgădui (do húngaro).

No concernente à aproximação ao português, quantas vezes eu própria tive que responder a perguntas sobre as chamadas "similitudes" que, de fato, não são maiores - e de longe - do que as existentes entre o espanhol e o português, ou o italiano, e o catalão e o romeno! Mas os romenos continuam a achar que nossas línguas são muito parecidas - um mito há muito tempo arraigado entre nós! A propósito disso mencionaria apenas que, caso único entre as línguas novilatinas, temos a mesma forma para o pronome pessoal de primeira pessoa do singular, derivada do ego, "eu"; que usamos, uns e os outros, fonemas inexistentes ou raros nas 
outras línguas românicas (como $\hat{a}, \breve{a}$ e muitos $c h$ ); e que "dispomos", uns e os outros, de uma gramática infernal, com inúmeras irregularidades!

Outra particularidade comum às duas línguas seria a possibilidade de grandes variações no tratamento das pessoas, dependentes do degrau de intimidade entre os interlocutores. Assim, temos um dumneavoastră muito formal, equivalente de "Vossa Excelência", e que se pode traduzir por "o Senhor", "a Senhora", etc. Temos depois um dumneata-ou, mais afetuoso, mata, matale, mătăluță - equivalente mais ou menos ao "você" tal como se usa em Portugal; temos, enfim, o "tu" que corresponde ao "tu" de Portugal e ao "você" do Brasil. Desta maneira, em O banqueiro anarquista pude utilizar sem hesitação a forma de dumneata, dado que entre os interlocutores do diálogo há uma certa familiaridade (mas não intimidade) que exclui tanto a primeira forma de tratamento, dumneavoastră, como o "tu".

Ao ler as crônicas de Pessoa, que me empenhei a dar a conhecer aos meus compatriotas, descobri com encanto que, igual às inúmeras máscaras pessoanas, aos conhecidos heterónimos, nessa obra em grande medida fragmentária encontram-se novos e novos disfarces através dos quais o autor transmite mensagens (muitas vezes cifradas, diz José Augusto Seabra). Dirigindo-se a múltiplos públicos durante a vida, ele não podia deixar de pensar também aos leitores futuros - isto é, em nós, que o lemos hoje, e nos romenos também, que puderam lê-lo enquanto atravessavam uma época de crise e de dilaceramentos complexos, que Pessoa pressentiu, aliás, já desde o começo do século passado.

Dos textos pessoanos que traduzi para romeno e publiquei como livros (porque fragmentos por mim traduzidos saíram já há algum tempo em revistas), o primeiro foi, em 1995, o diálogo O banqueiro anarquista, que eu tencionava inicialmente incluir numa antologia de contos portugueses, mas que, dada a sua importância e originalidade, decidi publicar separadamente, encontrando para isso um editor disposto a editar tal livro de dimensões reduzidas (o que os nossos editores muitas vezes recusam fazer, porque os custos da edição superam o preço da venda possível entre nós). O segundo livro foi uma coletânea a que tencionei dar o título pessoano Do contraditório como terapêutica de libertação, mas que o editor decidiu reduzir à Terapia da libertação (título de que gosto menos porque não contém o "remédio" recomendado por Pessoa - isto é, o contraditório -, que para nós, vindos duma época inimiga de toda oposição ou contradição, fazia parte integrante da 
libertação e das suas adquisições). Essa coletânea - na qual vou basear meu artigo - compreende tanto crônicas publicadas - ou recusadas pela Censura - nas primeiras décadas do século XX, como também fragmentos mais ou menos completos, mais ou menos datados. A maioria foram escritos pouco tempo depois de terminada a primeira guerra mundial portanto, pouco tempo também depois da instauração do comunismo na Rússia. Achei-os perturbadoramente premonitórios, e para nós, que saímos recentemente da noite do totalitarismo, de uma premente atualidade.

Agrupei os textos de maneira algo aleatória, em grandes linhas segundo três níveis de preocupações: a sociedade civil, a organização política da sociedade, as questões concernentes ao estudo das mentalidades. Mas, tal como o autor com os seus heterónimos - como já disse -, os escritos pessoanos têm numerosas facetas, podendo ler-se com várias chaves, sucessiva ou simultaneamente. Mas podem ler-se também um a um, contemplando-os o nosso olhar separadamente, como tantas joias independentes - sob o sinal do paradoxo: "Quaisquer opiniões opostas são absolutamente idênticas", ${ }^{4}$ diz Pessoa.

Sei bem que não se dissera tudo sobre Pessoa - porque nunca pode dizer-se tudo dum grande escritor - mas sei também que, pessoalmente, não tenho nada de novo e original a acrescentar ao que disseram os outros (das centenas de milhares de páginas escritas sobre Pessoa nas últimas décadas, verdadeiramente importantes seriam ao máximo 10.000!). Por conseguinte, se não posso propôr uma leitura inédita de Pessoa porque não sou capaz -, sugeriria em troca alguns temas de meditação para aqueles de entre os leitores que o frequentam regularmente: isto é, que apanham um dos seus livros, pelo menos para ler uma ou outra página, numa noite de insónia. Proponho pois, agora, a leitura de alguns dos seus textos com os olhos de um romeno no início do $3^{\circ}$ milénio!

Pessoa não foi um "especialista" em ciências sócio-humanas e políticas (como há tantos entre nós, hoje em dia!). Foi um grande intuitivo, um observador sensível dos fenómenos e acontecimentos, no seu país e algures, e foi também um pensador livre, original, denso e paradoxal. Paradoxal, pelo contraditório racional, e à margem da opinião comum, que julgava inautêntica.

\footnotetext{
${ }^{4}$ PESSOA, 2000, p. 171.
} 
Os temas e assuntos abordados são muitos e diversos, podendo a maioria deles oferecer ao leitor outras tantas ocasiões para meditar sobre a sociedade em geral, sobre a vida social e política romenas de hoje em especial, como também sobre o mecanismo mental gerador do social e político.

Trata-se de temas sobre a organização civil e política da sociedade, a estrutura e dinâmica social, a opinião pública, as doutrinas e práticas políticas, os partidos, a revolução, a tirania, a ditadura; podem acrescentar-se análises mais ou menos profundas dos conceitos de democracia, liberalismo, igualitarismo, fascismo, comunismo, etc.

Essencial para as considerações sobre a sociedade civil é a opinião pública. Ela é efeito da convivência de indivíduos do "meio interior" duma sociedade legitimada pela língua, as tradições e a pátria. É o "instinto social fundamental" de uma comunidade, e manifesta-se de maneira conservadora (como qualquer instinto), "não se adapta mas antes adapta as coisas a si" e ao ser contrariado torna-se antagonista: "Quem não é por mim é contra mim". 5 É uma orientação, uma atitude - não é uma ideia antes uma atmosfera, uma pressão; é pois não-intelectual'. Diz Pessoa: "não há nunca indicações positivas da opinião pública; todas as suas indicações são negativas, mau grado o seu carácter afirmativo de violência. A opinião pública nunca pede que: pede sempre que não."

O mesmo espírito paradoxal de Pessoa é patente também no texto intitulado: "A ilusão política das grandes manifestações populares" (título que podia fazer sonhar qualquer bucarestino de 1990!). "Para quem pensa - diz Pessoa - o único sentido duma manifestação importante é demonstrar que a corrente de opinião contrária é muito forte. [...] Quanto maior a manifestação, mais fraco está o visado; maior se sente a força que se lhe opõe."

No concernente à organização política - o outro domínio de reflexão de Pessoa - vejamos, como exemplo, a democracia moderna. Ela baseia-se em três princípios: o princípio do sufrágio (fundamento da vida política), o princípio do liberalismo (a tendência de abolir os privilégios de certas classes e pessoas e de instaurar a igualdade) e o princípio do pacifismo (sendo a paz o estado de normalidade entre os povos).

\footnotetext{
${ }^{5}$ PESSOA, 2000, p. 48.

${ }^{6}$ PESSOA, 2000, p. 60.

${ }^{7}$ PESSOA, 2000, p. 77 e 78.
} 
Será que o sufrágio exprime a "maioria real" da sociedade? É evidente que não, dado que a vida política da sociedade é organizada pelos partidos. O resultado do voto exprime apenas a organização dos partidos e a relação de forças entre eles, isto é, "a maioria política organizada" que, perante "a maioria real" da sociedade, é de facto uma "minoria". Em geral vence "aquele partido cuja organização puramente partidária deriva da superioridade dos organizadores partidários”, e os resultados de uma eleição "provam apenas o poder ditatorial que adquiriram os poucos indivíduos que são dirigentes do partido vencedor". ${ }^{8}$ Portanto, de uma eleição resulta apenas uma "pseudo-opinão pública". E como a opinião pública real é "popular, tradicionalista e patriótica", a democracia é paradoxalmente anti-popular, antitradicionalista e anti-patriótica e, baseando-se no sufrágio político, ela representa uma minoria possuidora dessas caraterísticas! Do ponto de vista da vida social, trata-se de um "intelectualismo", enquanto a opinião pública é um "fenómeno instintual".?

O liberalismo, segundo princípio fundamental da democracia, tem também um efeito paradoxal. A doutrina liberal encara o privilégio (isso é, as qualidades individuais naturais, a posição social em que nasce o indivíduo) não como "vantagem", mas como "estorvo". ${ }^{10}$ O liberalismo encara o privilégio do lado "de quem o não tem" e tende por conseguinte ao igualitarismo, "à abolição das diferenças" entre os indivíduos e os grupos sociais. Paradoxalmente, o liberalismo desapossa de liberdades a sociedade real (porque onde poderiam ser mais livres os indivíduos senão no exercício das suas qualidades naturais?), substituindo-lhes "os privilégios do capital" ou, ainda pior, "os do chamado trabalbo", o qual, sustido pela "classe popular" - "infelizes mentais cuja ignorância sociológica e desconhecimento da história os leva a [...] idéias socialistas ou parecidas, demência terminal do liberalismo", e à "ditadura do proletariado", "último avatar da ignorância e da asneira". ${ }^{11}$ Espero não ferir as sensibilidades de alguns dos leitores por essas citações pessoanas, mas, vindo de onde eu venho, falo... "en connaissance de cause".

\footnotetext{
${ }^{8}$ PESSOA, 2000, p. 50.

${ }^{9}$ PESSOA, 2000, p. 52.

${ }^{10}$ PESSOA, 2000, p. 54.

${ }^{11}$ PESSOA, 2000, p. 55.
} 
Agora, antes de passar ao terceiro princípio fundamental da democracia, gostaria de citar - paradoxalmente, claro! - uma perfeita definição do liberalismo, tal como o encara Pessoa:

O liberalismo é a doutrina que mantém que o indivíduo tem o direito de pensar o que quiser, de exprimir o que pensa como quiser, e de pôr em práctica o que pensa como quiser, desde que essa expressão ou essa práctica não infrinja directamente a igual liberdade de qualquer outro indivíduo. ${ }^{12}$

Não se podia dizer isso de maneira mais lapidar e clara.

Enfim, terceiro princípio da democracia, conforme Pessoa, o pacifismo é também um defeito do instinto social fundamental. Essa idéia diz respeito à concórdia entre os Estados, mas não diz respeito ao sentimento patriótico dos Estados, sentimento que, contrariado, se torna guerreiro. O pacifismo é um princípio ilusório de uma ilusória democracia, parece concluir Pessoa.

Para nós, Romenos, são interessantíssimas as considerações de Pessoa sobre a tessitura do mental individual e coletivo. A unidade fundadora é a unidade bumana, realizada tanto individual (o indivíduo singular) como coletivamente (o indivíduo plural), opostos que coincidem na unidade humana. Essa coincidência forma o mental - instintual, sentimental, intelectual.

Finalmente, qual seria a doença de que Pessoa pretende curar-nos, e qual a terapêutica recomendada por ele? A doença é o intelectualismo, com o seu sintoma maior - o dogma (a estase, a estagnação); o intelectualismo dogmático, com a sua expressão social - a tirania, a ditadura. A esse cancro que impede o movimento, pode aplicar-se um tratamento imunológico, com anticorpos. O anticorpo recomendado por Pessoa é o contraditório: nada corre sem ter o seu oposto. Ou então, como já citamos: "Quaisquer opiniões opostas são absolutamente idênticas".

O eventual impacto das reflexões de Pessoa sobre as realidades da sociedade contemporânea - romena e não só - teria podido ser importante tanto no concernente à sociedade civil como no que diz respeito à democracia.

Como consequência dos acontecimentos políticos internacionais das últimas quase duas décadas, surgiu a tendência de reconsiderar, repensar esses dois conceitos: sociedade civil, democracia.

12 PESSOA, 2000, p. 89. 
O que representa a sociedade civil atualmente e quais as suas funções? Ela perdeu tanto do seu poder, que hoje em dia quase não é capaz de determinar a organização política. No meu país, isso é tanto mais sério quanto a classe política está desligada do povo. E nota-se uma tendência similar no plano internacional. Os povos tendem a perder a sua identidade, o "instinto social fundamental", como dizia Pessoa, para se submeter à idéia política.

Quanto à democracia, as coisas parecem ainda mais complicadas. No meu país, à falta de um fator económico poderoso, a democracia tende a transformar-se num jogo interior à classe política, enquanto no plano internacional, por causa do fator económico poderoso, se converte num fenómeno pervertido pela globalização. Dum lado, uma falsa democracia, do outro lado, uma democracia ilusória. A democracia, esse mecanismo social que sempre oferece oportunidades iguais aos que pertencem ao sistema, quando não oferece também as condições e os meios iguais e legais de realização dessas oportunidades, permanece uma abstração. Sendo ao mesmo tempo uma experiência, uma construção concreta, cada povo tem que construir a democracia no seu próprio meio, baseando-se nos valores próprios, na aristocracia própria - como diz Pessoa -, isto é, nas competências próprias, nas suas caraterísticas reais.

Única como idéia e como projeto, a democracia não deve ser, no seu exercício real, idêntica, mas antes identitária, baseada no "instinto social fundamental" de cada construtor de democracia. Esta seria a lição de Fernando Pessoa.

Antes de terminar, não posso impedir-me de apresentar mais algumas citações que, sem dúvida, fizeram o encanto dos leitores romenos.

Assim, por exemplo, para nós, romenos, cuja "revolução" de 1989 é posta em dúvida e que não deixamos de perguntar, tal como Pessoa, "Houve uma revolução?", é óbvio que poderíamos tornar próprias as seguintes frases do poeta-pensador: "Tal é a história de todas as revoluções; por alto que seja o ideal onde se desempenharam, vêm sempre ter ao mesmo vale de sordidez humana". E isso porque "[...] um período revolucionário é sempre uma ditadura de inferiores". ${ }^{13}$

Inimigo de qualquer ditadura, Pessoa exprime-se assim ironicamente sobre a chamada "ditadura institucionalizada": "O argumento essencial

${ }^{13}$ PESSOA, 2000, p. 64. 
contra uma ditadura é que ela é ditadura, isto é, que é ilegal. O apresentarem os seus governos obra melhor, em um ou todos os sentidos, do que os governos legalmente constituídos não diminui a sua ilegalidade". ${ }^{14}$

O melhor regime político é aquele que permite com mais segurança e facilidade o jogo livre e natural das forças (construtivas) sociais, e que com mais facilidade permita o acesso ao poder dos homens mais competentes para exercê-lo. ${ }^{15}$

Um trecho a que afeiçoei particularmente contém os saborosos "Cinco diálogos contra a tirania", datados de 1918-1919, isto é, imediatamente após a instauração do regime ditatorial na Rússia. Qualquer sociedade civilizada - escreve Pessoa - caracteriza-se por a existência nela de dois elementos - a estabilidade e o progresso. Se não oferece estabilidade, resulta anárquica, e impossível o progresso; se não progride, não pode dizer-se uma sociedade civilizada. ${ }^{16}$

E agora, o curto diálogo conclusivo dos dois interlocutores:

Francisco - Uma idéia expressa é uma força; nunca é de mais fazer valer os direitos da Inteligência.

António - Uma idéia expressa é uma falta de força - da força de a calar. Os mestres ensinam pela palavra, mas é no silêncio que eles aprenderam. ${ }^{17}$

Um texto como "Régie, monopólio, liberdade", nesta nossa época de transição de uma sociedade fechada e ineficaz para uma sociedade aberta e de sucesso, é também de grande atualidade para nós. Diz Pessoa: "A administração de Estado só é admissível quando é inevitável, e só é inevitável num caso anormal, a guerra, e ainda assim, só para certas indústrias e comércios". E continua: "A administração pelo Estado [...] é prejudicial ao Estado, porque [...] mal administrado e prejudicial a si mesmo; [...] o consumidor é, no fim, quem paga o que deixa de pagar." 18 No comment, diríamos nós...

\footnotetext{
${ }^{14}$ PESSOA, 2000, p. 98.

${ }^{15}$ PESSOA, 2000, p. 96.

${ }^{16}$ PESSOA, 2000, p. 116.

${ }^{17}$ PESSOA, 2000, p. 118.

${ }^{18}$ PESSOA, 2000, p. 32.
} 
Também, no concernente à "Nova Europa", nesta nossa época de extensão da União Europeia, tem Pessoa alguma coisa de interessante que dizer:

Não pode haver esperança senão na introdução de princípios inteiramente novos na mentalidade europeia. Inteiramente novos? Digo mal: antes aqueles princípios que, sendo novos em aparência, são na realidade a tradição oculta de todo nosso estado civilizacional - os princípios gerais da nossa comum mãe helénica, e de Roma, a nossa matriz. ${ }^{19}$

E pensar que ele escreveu essas frases ainda durante a Primeira Guerra Mundial!

Os leitores romenos, que conheceram a tirania totalitária comunista por mais de quatro décadas, podem encontrar nos textos pessoanos razões para uma reflexão sobre a lógica que dirigia a opressão. Ao definir-se, numa "Nota biográfica" de 1935, na rubrica "Ideologia política", Pessoa considera que o sistema monárquico seria o mais próprio para uma nação organicamente imperial como é Portugal. Considera, ao mesmo tempo, a Monarquia completamente inviável em Portugal. Por isso, a haver um plebiscito entre regimes, votaria, com pena, pela República. Conservador de estilo inglês, isto é, liberal dentro o conservatismo, e absolutamente anti-reacionário... ${ }^{20}$

E como terminar, de maneira mais comovente, do que por esse "resumo" da "Nota biográfica": "[...] combater, sempre e em toda a parte, [...] a Ignorância, o Fanatismo e a Tirania"?21

Trabalhei a versão romena desses textos de Pessoa, não como mera tradutora, mas com o intento de chamar a atenção, sublinhar e difundir - duma maneira elegante e no estilo encantadoramente paradoxal e especificamente pessoano - ideias que pairavam, aliás, na atmosfera espiritual, social e política da Roménia, na última década do século passado. Por meio dessa coletânea - reduzida em tamanho, mas vastíssima na sua carga intelectual - quis provar que, na Roménia de hoje, também se pode falar de um Fernando Pessoa - nosso contemporâneo.

\footnotetext{
${ }^{19}$ PESSOA, 2000, p. 83.

${ }^{20}$ PESSOA, 2000, p. 14.

${ }^{21}$ PESSOA, 2000, p. 15.
} 


\section{Referências}

PESSOA, Fernando. Terapia eliberării. Bucureşti: Editura Ştiințifică, 2000.

\section{Resumo}

O artigo apresenta comentários à margem de várias crônicas de Fernando Pessoa datadas de 1918, 1919 e 1926, agrupadas algo aleatoriamente segundo três níveis de preocupações - a sociedade civil, a organização política e económica da sociedade, estudos das mentalidades. Sua tradução e publicação na Romênia contemporânea são de uma premente atualidade.

\section{Résumé}

L'article représente une série de commentaires en marge de différentes chroniques de Fernando Pessoa écrites en 1918, 1919 et 1926, groupées, de manière quelque peu aléatoire, selon trois niveaux de préoccupations - la société civile, l'organisation politique et économique de la société, études des mentalités - dont la traduction et publication dans la Roumanie contemporaine sont d'une pressante actualité. 